\title{
VISUAL OUTCOME AFTER LASER PHOTO COAGULATION IN DIABETIC RETINOPATHY
}

Tariq Qureshi, Ankur Goel, Waseem Raja, Anjum Bashir, Nowsheen Abdullah

1. Associate Professor. Department of Ophthalmology, Govt. Medical College, Srinagar, Kashmir.
2. Assistant Professor. Department of Ophthalmology, Govt. Medical College, Srinagar, Kashmir.
3. Assistant Professor. Department of Ophthalmology, Govt. Medical College, Srinagar, Kashmir.
4. Associate Professor. Department of Ophthalmology, Govt. Medical College, Srinagar, Kashmir.
5. Senior Resident. Department of Ophthalmology, Govt. Medical College, Srinagar, Kashmir.

\section{CORRESPONDING AUTHOR:}

Dr. Tariq Qureshi,

Associate Professor,

Postgraduate, Department of Ophthalmology,

Govt. Medical College, Srinagar.

E-mail: tariqqureshi317@gmail.com

Ph: 00919419007122

ABSTRACT: PURPOSE: To evaluate the visual outcome after laser photocoagulation in diabetic retinopathy. METHODS: One eye each of 100 patients were enrolled in our prospective, randomized, clinical trial study with proliferative diabetic retinopathy/ maculopathy were assessed for visual outcome after treating them with laser photocoagulation. RESULTS: We observed that $62(62 \%)$ patients showed improvement by 1 or more lines on Snell's chart, 26 (26\%) deteriorated from baseline visual acuity. The overall mean improved was 0.56 lines on Snell's chart that is clinically significant. CONCLUSION: The results of present collection of hundred patients show a favourable influence of photocoagulation on the improvement and preservation of baseline visual acuity. Timely focal and grid laser photocoagulation helps in improving and stabilizing the visual acuity in patients with diabetic macular edema.

KEYWORDS: Diabetic retinopathy, micro aneurysms, haemorrhages, laser, photocoagulation, exudates, retina, vitreous, maculopathy, ischemia.

SCOPE OF THE PROBLEM: Diabetic retinopathy is leading cause of blindness in whole of the world. The blindness is preventable. Timely diagnosis, investigations and treatment are hallmarks of the disease, but primary control of blood sugar, hypertension and renal failure are more important. The disease if not treated well in time leads to advanced diabetic eye disease features of which are tractional retinal detachment, vitreous haemorrhage and neovascular glaucoma and leads to permanent blindness.

Study was done to assess the stages of diabetic retinopathy to which the patient presents, duration of diabetes, mode of laser treatment to be applied and visual outcome after laser and to assess post laser complications.

INTRODUCTION : Diabetic retinopathy is progressive dysfunction of retinal vessels caused by chronic hyperglycemia ${ }^{1}$. It is a microangiopathy which primarily affects the precapillary arterioles, capillaries and post capillary venules although larger vessels may also be involved.

Risk Factors for Diabetic Retinopathy: Presence of diabetes itself ${ }^{2}$, duration of diabetes, poor metabolic control, pregnancy associated with progression of diabetic retinopathy, hypertension, 
smoking, obesity and hyperlipidemia. Diabetic retinopathy has features of both microvascular occlusion and leakage.

Diabetic Maculopathy: Changes in macular region need special mention, due to their effect on vision. These changes may be associated with non-proliferative diabetic retinopathy (NPDR) or proliferative diabetic retinopathy (PDR). It is termed as Clinically Significant Macular Edema (CSME) $)^{3,4}$ if one of the following three criteria are present.

Thickening of retina at or within 500 micron of the centre of the fovea, hard exudates at or within 500 micron of the centre of the fovea associated with adjacent retinal thickening, development of a zone of retinal thickening one disc diameter or larger in size, at least a part of which is within one disc diameter of the foveal centre.

Clinico-angiographically diabetic retinopathy can be classified as ${ }^{5,6}$ :

- $\quad$ Focal exudative maculopathy

- $\quad$ Diffuse exudative maculopathy

- Ischaemic maculopathy

- $\quad$ Mixed maculopathy

\section{MANAGEMENT:}

1. Screening:

To prevent visual loss occurring from diabetic retinopathy a periodic follow up is very important for a timely intervention.

\section{Medical Treatment ${ }^{7,8}$}

Control of systemic risk factors like strict metabolic control of blood sugar, lipid reduction, role of pharmacological modulations include protein kinase C (PKC) inhibitor, VEGF inhibitors, aldolase reductase and ace inhibitors. Role of intravitreal steroids like intravitreal triamcinolone acetonide $(2-4 \mathrm{mg})$ in reducing macular edema.

\section{Laser Photocoagulation}

Laser light is monochromatic, unidirectional, coherent and collimated.

\section{Laser Photocoagulation for Diabetic Macular Edema ${ }^{4,9}$}

- Focal Laser: for all focal leaks located between 50000-30000 from the centre of macula.

- Grid Laser: All areas of thickened retina within the arcade are treated with 1000 to 200? spot size placed one burn width apart at 0.1 second duration. Treatment within papillomacular bundle is usually avoided. 


\section{Sequence of PRP Steps ${ }^{10}$}

Step - 1: Inferior retina below the inferior temporal arcade.

Step - 2: Protective barrier around the macula to prevent inadvertent treatment of the fovea above the superotemporal arcade.

Step - 3: Nasal to the disc completion of the posterior pole treatment.

Step - 4: Peripheral treatment until completion.

Complication of Laser Photocoagulation ${ }^{11,12,13}$ These include accidental foveal burns, macular edema and macular pucker, pre-retinal fibrosis, hemorrhage from retina and choroid, tractional retinal detachment, retinal hole formation, ischaemic papillitis.

The laser photocoagulation burns and destroys part of the retina and often results in some permanent vision loss. Mild loss of central vision, reduced night vision and decreased ability to focus. Iris burns and choroidal effusion.

4. Surgical Treatment of Diabetic Retinopathy : Pars plana vitrectomy for treating severe complications of PDR like severe persistent vitreous haemorrhage, progressive tractional retinal detachment, combined tractional and rhegmatogenous retinal detachment, pre-macular sub-hyaloid hemorrhage.

MATERIALS AND METHODS : This hospital based study was conducted in the Postgraduate Department of Ophthalmology, SMHS Hospital of Government Medical College, Srinagar. 100 patients with proliferative diabetic retinopathy/ maculopathy were assessed for visual outcome after treating them with laser photocoagulation. After adequate pupillary dilatation is achieved, the patient is seated in front of laser machine. Eye is anaesthetized with $2 \%$ lidocaine hydrochloride. Laser applied, "100-200? $\mathrm{m}$ spot size, one burn width apart $0.1 \mathrm{sec}$ for grid pattern”. For PRP 200-500? m spot size, one burn apart0.1 sec. The laser was irradiated on the area 500-3000? $\mathrm{m}$ from the macular center at the thickened retina showing capillary blood vessel occlusion and considered to be the origin of the leakage in the focal, diffuse leakage areas as shown by Fluorescein Fundus Angiography. In other words the area showing initial hyperfluorescence was irradiated.

Baseline and follow-up examination was performed at 1 week, 4 weeks, 6 weeks, 3 months after treatment using the Snellen's chart of the patient, best corrected visual acuity (BCVA) [Log MAR] was measured.

OBSERVATIONS AND STATISTICAL ANALYSIS (OUTCOME): Data was expressed as mean \pm SD and percentages. All the parametric variables were analyzed by Students ' $t$ ' test whereas nonparametric variables were compared by Mann Whittney ' $U$ ' test. P-value of less than $<0.05$ was considered statistically significant. Software used was Statistical Package for Social Sciences (SPSS) Version 11.5, Minitab 14.0 and MS Excel 2007.

The sample consisted of 100 patients out of which 47 were males and 53 were females. Males were in mean age group of 54.2years with SD of _+8.5 years (range 30-74years).Females were in mean age group of 54.0years with SD of _+8.0 years(range 32-65 years).The difference between the two was not clinically significant. 
DISCUSSION: With changing life style and more urbanization, diseases like diabetes and hypertension have become more common, leading to a greater prevalence of diabetes and hypertensive retinopathy.

The purpose of our study was to examine one eye each of 100 cases of diabetic retinopathy and to find out visual outcome after laser photocoagulation in them. In present study, 100 diabetic patients were analyzed in which 96 patients belonged to type 2 diabetes mellitus and 4 patients belonged to type 1 diabetes mellitus. The age range was between 30-74 years with mean age of 54.1 years with SD of \pm 8.2 years, $47 \%$ were males, $53 \%$ were females ${ }^{14}$. The maximum incidence of diabetic retinopathy requiring laser therapy was found in the age group of 50-59 years. This does not coincide with age group stated by Duke Elder ${ }^{14}$. Duration of diabetes was between age range of 4-28 years with mean 14.7 years with SD of \pm 6.1 years.

Laser was performed in hundred patients with visual acuity range between 6/9-3/60. Follow up examination was performed after every 4-6 weeks upto 3 months period. Following laser treatment BCVA improved in $62 \%$ of patients, unchanged in $26 \%$ and deteriorated in $12 \%$ of patients. Visual outcome improved in $62 \%$ (mean 0.56 line improvement) which is statistically significant and is in agreement with the studies done by others. This is in close tally with the study done by Shreshta S, Karki DB, Byanju et al (2007) ${ }^{15}$ which found that following laser treatment, BCVA improved in $52.50 \%$, remained static in $35 \%$ and deteriorated in $12.5 \%$ of patients after one year follow up. The post-treatment visual acuity was significant $(\mathrm{p}=0.038$ ) in this study.

Following laser therapy in maculopathy patients, BCVA improved in 33.3\%, unchanged in $53.3 \%$ and deteriorated in $13.3 \%$ of patients with mean 0.3 line improvement. However a study done by Toke Bek, Flemming Moller and Boilel Khalusen in 2007 concluded that an average visual acuity was unchanged 3 months after laser photocoagulation for diabetic maculopathy with change in BCVA range between -0.44 to 0.33 (mean -0.04).

Following laser therapy in severe NPDR with maculopathy $100 \%$ of the patients improved with mean 1.3 line improvement while following laser therapy in PDR with maculopathy $63.6 \%$ improved, $18.2 \%$ remain unchanged and $18.2 \%$ deteriorated with 0.3 line improvement. This is in accordance with the study done Dr Y.K. Dastur (1994) ${ }^{16}$.

In our study following PRP and grid, 71.4 patients improved, $14.3 \%$ patients remain unchanged while $14.3 \%$ deteriorated. These results are in close tally with the study done by Havska et al. (2009) ${ }^{17}$.

In our study, duration of diabetes is found to be closely related to the BCVA after laser therapy. In our study, $25 \%$ of eyes deteriorated in patients with duration of diabetes $>20$ years as compared to $15.4 \%$ of eyes deteriorated in patients $\leq 10$ years duration of diabetes mellitus. $76.9 \%$ of eyes improved in patients with $\leq 10$ years duration, $62.1 \%$ eyes improved in 11 to 20 years duration whereas only $37.5 \%$ of eye improved in $>20$ years duration.

The comparison between duration of diabetes and BCVA after laser therapy was found statistically significant $(\mathrm{p}=0.046)$. The correlation between the two $(r=-0.225)$ which shows the inverse relationship between the duration of diabetes and the visual outcome after laser. This is in accordance with the study done by Mohan Rema et al and some others. ${ }^{18}$

In our study, $55 \%$ of the patients with baseline visual acuity between 6/6-6/18 shows improvement and $73.9 \%$ of the patients between $6 / 24$ to $6 / 60$ shows improvement after laser as compared to only $42.9 \%$ of patients with baseline visual acuity $<6 / 60$. Only $4.3 \%$ of patients with baseline visual acuity of $6 / 24$ or $6 / 60$ shows deterioration as compared to $14.3 \%$ of patients with baseline visual acuity of $<6 / 60$. The comparison between the two parameters was 
found clinically significant but statistically insignificant. However there are studies done by others $^{19,20,21}$ found a statistically significant relations between the two. The variation in my study may be due to shorter follow up time and different clinical profile of the patients.

\section{CONCLUSION:}

- The results of presented collection of hundred patients shows a favourable influence of photocoagulation on the improvement and preservation of baseline visual acuity.

- Timely focal and grid laser photocoagulation helps in improving and stabilizing the visual acuity in patients with diabetic macular edema.

- $\quad$ Contrary to popular belief that PRP is associated with worsening of macular edema, we found that PRP + grid laser done for co-existent PDR and severe NPDR did not lead to worsening of treatment outcome. PRP done in severe NPDR / PDR patients associated with diabetic maculopathy has beneficial effects in stabilizing the visual acuity and reducing diabetic macular edema.

- Laser photocoagulation done in severe NPDR patients approaching high risk characteristics PDR helps in stabilizing the visual acuity and prevents vision threatening complications.

- Increasing duration of diabetes is associated with less favourable visual outcome after laser photocoagulation in diabetic patients.

\section{BIBLIOGRAPHY}

1. Foulds WS, Maccuish AC, Barrie T. The cost effectiveness of screening for diabetic retinopathy. Seminars in Ophthalmology 1987; 2: 45-50.

2. Klein R, Klein B, Moss $\mathrm{S}$ et al. The Wisconsin epidemiologic study of diabetic retinopathy XIV. Ten years incidence and progression of diabetic retinopathy. Arch Ophthalmol 1994; 112: 1217-28.

3. Partz A, Schatz H, Berkow J et al. Macular edema: an overlooked complication of diabetic retinopathy. Trans Am Acad Ophthalmol Otolaryngol 1973; 77: 34-42.

4. Early Treatment Diabetic Retinopathy Research Group. Photocoagulation for diabetic macular edema. EIDRS Report 1. Arch Ophthalmol 1985; 103: 1796-1806.

5. Brensick GH. Diabetic maculopathy a critical review highlighting diffuse macular edema. Ophthalmology 1983; 90: 1301-1317.

6. Brensick GH. Diabetic macular edema - a review. Ophthalmology 1986; 104: 989-997.

7. Diabetic Retinopathy Clinical Research Network (CRCR.net) Beck RW, Edward AR, Mello LP et al. Three year follow up of a randomized control trial comparing focal/grid photocoagulation and intravitreal triamcinolone for diabetic macular edema. Arch Ophthalmol. 2009; 127(3): 1245-51.

8. Mortidis A, Dukes JS, Greenberg PB et al. Intravitreal triamcinolone for refractory diabetic macular edema. Ophthalmology 2002; 109: 920-7.

9. Early Treatment Diabetic Retinopathy Study Research Group. Treatment, techniques and clinical guidelines for photocoagulation of diabetic macular edema. ETDRS Report No. 2. Ophthalmology 1987; 84: 761-774.

10. Early Treatment Diabetic Retinopathy Study Research Group. Techniques for scatter and local photocoagulation treatment for proliferative diabetic retinopathy. Early Diabetic Retinopathy Study Report No. 3. Int Ophthalmol Clin 1987; 27: 254-64. 
11. Early Treatment Diabetic Retinopathy Research Group. Subretinal fibrosis in diabetic macular edema. ETDRS Report 2, 3. ACTga Ophthalmol 1997; 115: 873-77.

12. Rivellese M, George A, Sulkes D, Reichel E, Puliafilo C. Ocular coherence tomography after laser photocoagulation for clinically significant macular edema. Ophthalmol Surg Lasers 2003; 31(3): 192-97.

13. Kremser BG, Fulls M, Kieselbach GF. Influence of lipid fractions on the course of diabetic macular edema after photocoagulation. Ophthalmologic 1995; 269: 60-63.

14. Steward Duke-elder, John M. Dobree. System of Ophthalmology Volume X: 408-445.

15. Shrestha S, Karki DB, ByanjuR, Mulla DK, Shreshtha SM, Pradhananga CL. Visual outcome of laser treatment in diabetic retinopathy. Kathmandu Univ M. Journal 2007; 5(1): 7280.

16. Dastus YK. The rationale of argon green laser photocoagulation for diabetic maculopathy. J Postgrad Med 1994; 40(1): 13-17.

17. Havska M. The effect of photocoagulation on visual acuity in diabetic patients suffering from diabetic macular edema. Bratisl Lek Listy Lek Listy 2009; 110(7): 419-422.

18. Rema Mohan, Sujatha Purushothaman, Pradeepa Rajendra. Visual outcomes of PRP in diabetic retinopathy at one year follow up associated risk factors. 2005; 53(2): 93-99.

19. Gupta A, Gupta V, Dogra MR, Pandaw SS. Risk factors influencing the treatment outcome in diabetic macular edema. Ind J Ophthalmol 1996; 44: 145-148.

20. Rema Mohan, Sujatha Purushothaman, Pradeepa Rajendra. Visual outcomes of PRP in diabetic retinopathy at one year follow up associated risk factors. 2005; 53(2): 93-99.

21. K. Kausthal, J. P. New, D. McDowell, L.B. Young, R. Taylor, R.J. Young. To identify factors that predict visual outcome after laser treatment for sight threatening diabetic retinopathy. (STDR) in routine care. Practical Diabetes Int 2002; 19(1): 6-9.

\begin{tabular}{|c|c|c|c|c|c|c|c|}
\hline \multicolumn{8}{|c|}{ Table - 1Age and Gender distribution of the Patients } \\
\hline \multirow{2}{*}{ Age (yr) } & \multicolumn{2}{|c|}{ Male } & \multicolumn{2}{|c|}{ Female } & \multicolumn{2}{|c|}{ Total } & \multirow{2}{*}{$\mathrm{p}$ value } \\
\hline & $\mathrm{n}$ & $\%$ & $\mathrm{n}$ & $\%$ & $\mathrm{n}$ & $\%$ & \\
\hline 30 to 39 & 2 & 4.3 & 4 & 7.5 & 6 & 6.0 & \multirow{6}{*}{$\begin{array}{c}0.846 \\
(\mathrm{NS})\end{array}$} \\
\hline 40 to 49 & 9 & 19.1 & 9 & 17.0 & 18 & 18.0 & \\
\hline 50 to 59 & 23 & 48.9 & 23 & 43.4 & 46 & 46.0 & \\
\hline$\geq 60$ & 13 & 27.7 & 17 & 32.1 & 30 & 30.0 & \\
\hline Total & 47 & 47.0 & 53 & 53.0 & 100 & 100.0 & \\
\hline mean $\pm S D$ & \multicolumn{2}{|c|}{$\begin{array}{c}54.2 \pm 8.5 \\
(30,74)\end{array}$} & \multicolumn{2}{|c|}{$\begin{array}{c}54.0 \pm 8.0 \\
(32,65)\end{array}$} & \multicolumn{2}{|c|}{$\begin{array}{c}54.1 \pm 8.2 \\
(30,74)\end{array}$} & \\
\hline
\end{tabular}

The sample consisted of 100 patients out of which 47 were males and 53 were females. Males were in mean age group of 54.2years with SD of_+8.5 years (range 30-74years).Females were in mean age group of 54.0years with SD of _+8.0 years(range 32-65 years).The difference between the two was not clinically significant. 


\begin{tabular}{|c|c|c|c|c|c|c|c|}
\hline \hline \multicolumn{7}{|c|}{ Table - 2 Duration of Diabetes (yr) in the Patients } \\
\hline \multirow{2}{*}{ Duration of Diabetes (yr) } & \multicolumn{2}{|c|}{ Male } & \multicolumn{1}{c|}{ Female } & \multicolumn{2}{|c|}{ Total } & \multirow{2}{*}{ p value } \\
\cline { 2 - 7 } & $\mathbf{n}$ & $\mathbf{\%}$ & $\mathbf{n}$ & $\mathbf{\%}$ & $\mathbf{n}$ & $\mathbf{\%}$ & \\
\hline$\leq 5$ & 5 & 10.6 & 5 & 9.4 & 10 & 10.0 & \\
\hline 6 to 10 & 6 & 12.8 & 10 & 18.9 & 16 & 16.0 & \\
\hline 11 to 15 & 11 & 23.4 & 13 & 24.5 & 24 & 24.0 & \multirow{2}{*}{0.471} \\
\hline 16 to 20 & 16 & 34.0 & 18 & 34.0 & 34 & 34.0 & \multirow{2}{*}{ (NS) } \\
\hline$>20$ & 9 & 19.1 & 7 & 13.2 & 16 & 16.0 & \\
\hline mean \pm SD & $14.8 \pm 6.3$ & $14.7 \pm 6.0$ & $14.7 \pm 6.1$ & \\
& $(4,28)$ & $(4,26)$ & $(4,28)$ & \\
\hline
\end{tabular}

Table above depicts that there were 10 patients $(10 \%)$ with <_5year duration of diabetes,16 patients (16\%) within 6-10year duration,24 patients (24\%) within 16-20 year duration and 16 patients with $>20$ year duration with mean duration of diabetes of 14.7 with SD of +_6.1years (range 4 to 28 years).

\begin{tabular}{|c|c|c|c|c|c|c|}
\hline \multicolumn{7}{|c|}{ Table - 3 Diagnosis across Type of Diabetes } \\
\hline \multirow{2}{*}{ Diagnosis } & \multicolumn{2}{|c|}{ Type 1 } & \multicolumn{1}{c|}{ Type 2 } & \multicolumn{2}{c|}{ Total } \\
\cline { 2 - 7 } & $\mathbf{n}$ & $\mathbf{\%}$ & $\mathbf{N}$ & $\mathbf{\%}$ & $\mathbf{n}$ & $\mathbf{\%}$ \\
\hline Severe NPDR & 0 & 0.0 & 4 & 4.2 & 4 & 4.0 \\
\hline Maclopathy & 0 & 0.0 & 30 & 31.3 & 30 & 30.0 \\
\hline Proliferative DR & 2 & 50.0 & 34 & 35.4 & 36 & 36.0 \\
\hline Proliferative DR and Maclopathy & 0 & 0.0 & 22 & 22.9 & 22 & 22.0 \\
\hline Severe NPDR withMaclopathy & 2 & 50.0 & 6 & 6.3 & 8 & 8.0 \\
\hline
\end{tabular}

Above table depicts that out of 4 patients with type1 DM, 2 patients belong to PDR and 2 patients belong to severe NPDR with maculopathy. In type2 DM, out of 96 patients 4 presented with severe NPDR, 30 with maculopathy, 36 with PDR, 22 with PDR with maculopathy and 8 with severe NPDR with maculopathy.

\begin{tabular}{|c|c|c|c|c|c|c|}
\hline \multicolumn{7}{|c|}{ Table - 4 Intervention } \\
\hline \multirow{2}{*}{ Intervention } & \multicolumn{2}{|c|}{ Right } & \multicolumn{2}{c|}{ Left } & \multicolumn{2}{|c|}{ Total } \\
\cline { 2 - 7 } & $\mathbf{n}$ & $\mathbf{\%}$ & $\mathbf{N}$ & $\mathbf{\%}$ & $\mathbf{n}$ & $\mathbf{\%}$ \\
\hline PRP & 16 & 29.6 & 18 & 39.1 & 34 & 34.0 \\
\hline GRID & 14 & 25.9 & 2 & 4.3 & 16 & 16.0 \\
\hline FOCAL & 8 & 14.8 & 12 & 26.1 & 20 & 20.0 \\
\hline PRP + GRID & 6 & 11.1 & 8 & 17.4 & 14 & 14.0 \\
\hline PRP + FOCAL & 10 & 18.5 & 6 & 13.0 & 16 & 16.0 \\
\hline
\end{tabular}

Above table shows that PRP was done in 34(34\%) patients. PRP+grid and PRP+focal was done in $14(14 \%)$ \& 16 (16\%) patients respectively. Grid and Focal was done in 16 (16\%) and 20 (20\%) patients respectively. 


\begin{tabular}{|c|c|c|c|c|c|c|c|}
\hline \multicolumn{8}{|c|}{ Table - 50verall results of BCVA } \\
\hline \multirow{2}{*}{ BCVA } & \multicolumn{2}{|c|}{ Baseline } & \multicolumn{2}{|c|}{ First Visit } & \multicolumn{2}{|c|}{ Final Visit } & \multirow{2}{*}{ Result } \\
\hline & $\mathbf{n}$ & $\%$ & $\mathbf{N}$ & $\%$ & $\mathbf{n}$ & $\%$ & \\
\hline $6 / 9$ & 2 & 2 & 10 & 10 & 12 & 12 & \multirow{7}{*}{$\begin{array}{l}\text { a: } p=0.000(\mathrm{Sig}) \\
\text { b: } p=0.000(\mathrm{Sig}) \\
\text { c: } p=0.176(\mathrm{NS}), \\
\mathrm{d}: \mathrm{p}=0.000(\mathrm{Sig})\end{array}$} \\
\hline $6 / 12$ & 16 & 16 & 16 & 16 & 18 & 18 & \\
\hline $6 / 18$ & 22 & 22 & 26 & 26 & 22 & 22 & \\
\hline $6 / 24$ & 18 & 18 & 18 & 18 & 22 & 22 & \\
\hline $6 / 36$ & 18 & 18 & 16 & 16 & 12 & 12 & \\
\hline $6 / 60$ & 10 & 10 & 6 & 6 & 4 & 4 & \\
\hline$<6 / 60$ & 14 & 14 & 8 & 8 & 10 & 10 & \\
\hline
\end{tabular}

a - comparison between baseline and first visit visual acuity

$\mathrm{b}$ - comparison between baseline and final visit visual acuity

c - comparison between first visit and final visit visual acuity

$\mathrm{d}$ - overall comparison

We observed that after comparing baseline visual acuity with BCVA at $1^{\text {st }}$ visit, there was a statistically significant improvement seen $(p=0.000)$. There was significant improvement between baseline visual acuity and BCVA at final visit ( 3 months $)(p=0.000)$. Overall comparison shows significant improvement $(\mathrm{p}=0.000)$.

\begin{tabular}{|c|c|c|c|c|c|c|}
\hline \multicolumn{7}{|c|}{ Table - 6 Baseline to final visit improvement } \\
\hline \multirow{2}{*}{ Baseline to final visit improvement } & \multicolumn{2}{|c|}{ Right } & \multicolumn{2}{|c|}{ Left } & \multicolumn{2}{c|}{ Total } \\
\cline { 2 - 8 } & $\mathbf{n}$ & $\mathbf{\%}$ & $\mathbf{n}$ & $\mathbf{\%}$ & $\mathbf{n}$ & $\mathbf{\%}$ \\
\hline-2 & 2 & 3.7 & 2 & 4.3 & 4 & 4.0 \\
\hline-1 & 4 & 7.4 & 4 & 8.7 & 8 & 8.0 \\
\hline 0 & 12 & 22.2 & 14 & 30.4 & 26 & 26.0 \\
\hline 1 & 30 & 55.6 & 22 & 47.8 & 52 & 52.0 \\
\hline 2 & 6 & 11.1 & 4 & 8.7 & 10 & 10.0 \\
\hline Mean & \multicolumn{2}{|c|}{0.63} & \multicolumn{2}{|c|}{0.48} & \multicolumn{2}{c|}{0.56} \\
\hline
\end{tabular}

We observed that 62 (62\%) patients showed improvement by 1 or more lines on Snells chart, $26(26 \%)$ remains unchanged and $12(12 \%)$ deteriorated from baseline visual acuity. The overall mean improvement was 0.56 lines on Snell`s chart that is clinically significant.

\begin{tabular}{|c|c|c|c|c|c|c|}
\hline \multicolumn{7}{|c|}{ Table - 7 Post Laser Complications (if any) } \\
\hline $\begin{array}{c}\text { Complications } \\
\text { (if any) }\end{array}$ & \multicolumn{2}{|c|}{ Right } & \multicolumn{2}{c|}{ Left } & \multicolumn{2}{c|}{ Total } \\
\cline { 2 - 7 } & $\mathbf{n}$ & $\mathbf{\%}$ & $\mathbf{n}$ & $\mathbf{\%}$ & $\mathbf{n}$ & $\mathbf{\%}$ \\
\hline None & 46 & 85.2 & 42 & 91.3 & 88 & 88.0 \\
\hline Epiretinal Membrane & 2 & 3.7 & 0 & 0.0 & 2 & 2.0 \\
\hline Non Resolving ME & 4 & 7.4 & 2 & 4.3 & 6 & 6.0 \\
\hline Tractional R.D & 2 & 3.7 & 0 & 0.0 & 2 & 2.0 \\
\hline Vitrous Hemmorrhage & 0 & 0.0 & 2 & 4.3 & 2 & 2.0 \\
\hline
\end{tabular}

Above table shows that non resolving macular edema was present in 6(6\%) patients followed by vitreous hemorrhage, epiretinal membrane, tractional RD, all are present in $2(2 \%)$ patients each. 


\section{ORIGINAL ARTICLE}

\section{LENSES USED FOR MACULAR PHOTOCOAGULATION}
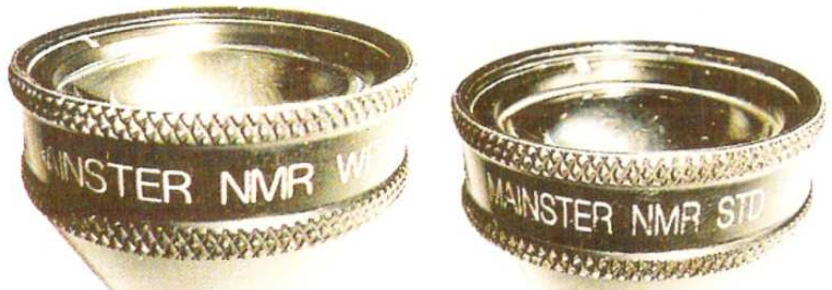

Mainster Wide Field Lens

Mainster Standard Lens

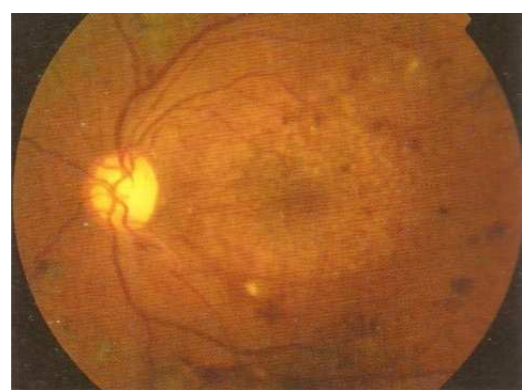

Grid Laser Spots

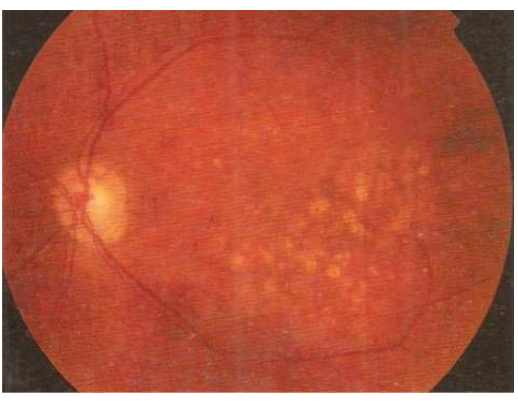

Focal Laser Spots
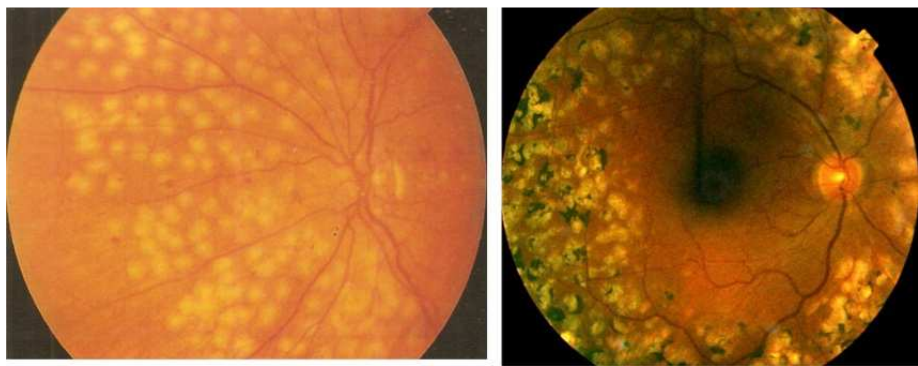

Laser Scars
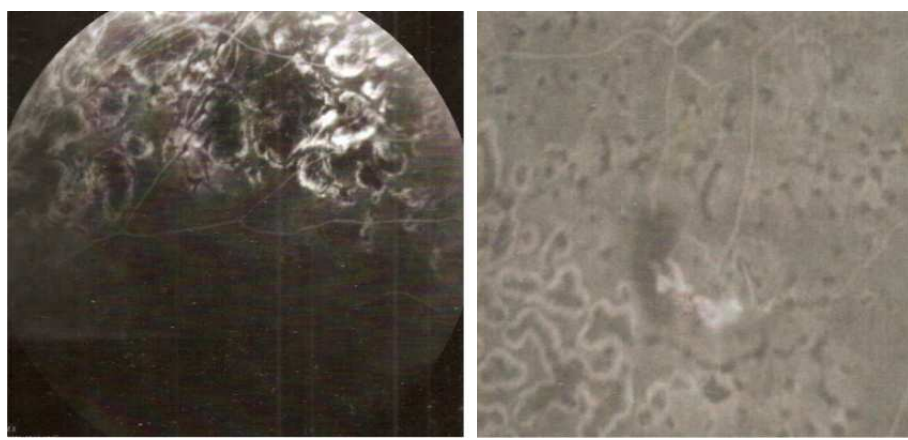

Sectoral Laser Spot Laser Spots Resolving Neovascularization 